\title{
Genetic Variability of FABP4 c.328 G>A (rs110652478) Polmorphism and Its Association with Slaugter Weight and Carcass Traits in Aberdeen Angus and Hereford Bulls Imported into Turkey
}

\author{
๑ Sena Ardıçlı1 ${ }^{1}$ ๑ Hakan Üstüner², ๑ Öznur Arslan ${ }^{2}$
}

1Department of Genetics, Faculty of Veterinary Medicine, Bursa Uludag University, Nilufer/Bursa, 16059, Turkey

2Department of Animal Science, Faculty of Veterinary Medicine, Bursa Uludag University, Nilufer /Bursa, 16059, Turkey

Received 25-03-2021 Accepted 09-06-2021

\begin{abstract}
The study aimed to determine the genotypic distribution of the c.328 G>A (rs110652478) polymorphism in the bovine fatty acid-binding protein 4 (FABP4) gene and to determine its effect on slaughter weight in Aberdeen Angus and Hereford bulls imported into Turkey. A total of randomly selected 95 bulls were used in this study. Bulls were housed for fattening in semi-open pens for approximately nine months with the same management procedures. Genotyping of the FABP4 c.328 G>A (rs110652478) polymorphism, located in exon 3, was performed by the PCR-RFLP method. Allele and genotype frequencies were calculated by the standard procedures and the Hardy-Weinberg equilibrium was tested by comparing expected and observed genotype frequencies using chi-square and Fisher's exact tests. Indices of genetic diversity were calculated based on the allelic frequencies. The least-squares method as applied in a GLM procedure was used to test the association between FABP4 c.328 G>A and phenotypic traits including slaughter weight, hot and cold carcass weight, chilling loss, dressing percentage, and carcass pH. Results revealed that the most frequent genotype was GG (49.18\% and 52.94\% for Angus and Herefords, respectively) and the minor allele frequency (A allele) was 0.32 in the total population. The genotype distribution was in agreement with Hardy Weinberg equilibrium ( $P>0.05)$. The moderately low levels of genetic variability observed in this study may be caused as a result of eventual inbreeding. PIC levels suggest that FABP4 c.328 G $>A$ can be a mildly informative genetic marker for the tested population. Association analysis indicated that the effect of the FABP4 on slaughter weight was statistically significant $(\mathrm{P}<0.05)$ in the total population. However, this association was not substantiated in breed-specific analyzes. There was no significant effect of the marker on any remaining phenotypic traits. Consequently, it is important to emphasize that analysis of FABP4 c.328 G>A may provide valuable, but limited, information on imported beef cattle raised in Turkey conditions.
\end{abstract}

Keywords: Beef cattle, FABP4, single nucleotide polymorphism, marker-assisted selection

\section{Introduction}

In recent years, parallel to biotechnology developed in the field of molecular genetics, in particular, the opportunity to conduct more detailed research at the molecular level has enabled the development of new methods and increased availability. Traditional genetic improvement of livestock, using the information on phenotypes and pedigrees to predict breeding values, has been very successful. However, breeding values should be able to predict more accurately by using genomic data between animals. ${ }^{1}$ Moreover, genetic selection methods have the ability to reduce the generation interval which is a crucial point in livestock, especially for cattle breeding. Concerning beef cattle, it is worth noting that the selection based on the traits that can be detected after slaughter (or traits that emerge in the later stages of animals' life) with classical selection methods requires a long period and can lead to economic losses. Thus, molecular genetic studies allow many traits to be evaluated when the animal is still alive and that these data can be used in early selection. ${ }^{2,3}$

The use of genetic markers increases the frequency of desired genes in herds based on the selection in breeding programs. In this context, many candidate genes have been identified as potentially associated with the specific traits analyzed. Among them, fatty acid-binding protein ${ }^{4}$

* Corresponding author: Bursa Uludag University Faculty of Veterinary Medicine Department of Genetics Tel: (+90)5414875448

E-mail: sardicli@uludag.edu.tr 
(FABP4), which was mapped to BTA14, is one of the most important genes in cattle breeding. The main function of this gene is to play a regulative role in lipid metabolism associated with changes in lipid hydrolysis and intracellular fatty acid. ${ }^{4}$ It is also essential for glucose homeostasis through interaction with peroxisome proliferator-activated receptors. ${ }^{5}$ The protein encoded by the FABP4 gene (GenBank accession number: NC_007312) is a cytoplasmic protein that binds long-chain fatty acids and other hydrophobic ligands. ${ }^{6}$ Taken together, this gene has been suggested as a functional and positional candidate gene for the evaluation of fat synthesis dynamics in cattle. ${ }^{7-9}$ Although FABP4 gene shows its main effects on meat quality, ${ }^{5,10}$ it is also of great importance in terms of some carcass characteristics. ${ }^{2,11,12}$ The c.328 G>A polymorphism (rs110652478) in the bovine FABP4 gene is located on exon 3 and it induces valine to methionine substitution at position $110 .^{8,9}$ This SNP has been associated with desirable increases in marbling scores and meat quality grades., ${ }^{2,8}$

In Turkey, the supply and demand balance in beef has been tried to be regulated mostly by the importation of live animals or carcasses. There is limited information about the genetic characteristics and/or structure of the imported beef cattle. Even their breed purity can be controversial. Although genetic analysis has become more widespread in dairy cattle, this approach is mostly not adopted in beef cattle in Turkey. Indeed, the genomic evaluation will provide significant insights into consistent selection strategies for not only raising cattle but also for selecting individuals with a superior performance before importation into Turkey. Therefore the main objective of this study was to evaluate the genetic diversity of FABP4 c.328 G>A (rs110652478) polymorphism in Aberdeen Angus and Hereford bulls. Moreover, their slaughter weights and some carcass characteristics were evaluated following a fattening period in Turkey conditions.

\section{Materials and Methods}

\section{Animals and sampling}

A total of 95 Aberdeen Angus $(n=61)$ and Hereford $(n=34)$ bulls from a commercial farm located in the South Marmara region $\left(40^{\circ} 15^{\prime} 28.04^{\prime \prime} \mathrm{N}\right.$ and $\left.29^{\circ} 30^{\prime} 50.18^{\prime \prime} \mathrm{E}\right)$ of Turkey were used. The cattle were transported from Brazil to Bursa province of Turkey. All cattle were housed for fattening in semi-open pens for approximately nine months under the same environmental conditions and management procedures (Figure 1). At the end of the fattening period, the animals were slaughtered at a commercial slaughterhouse based on standard practices. During exsanguination, $4 \mathrm{~mL}$ of the blood sample was obtained into a sterile K3EDTA tube (Vacutest Kima, SRL, Italy) from flowing blood.
Figure 1. Animal material and environmental conditions in the present study

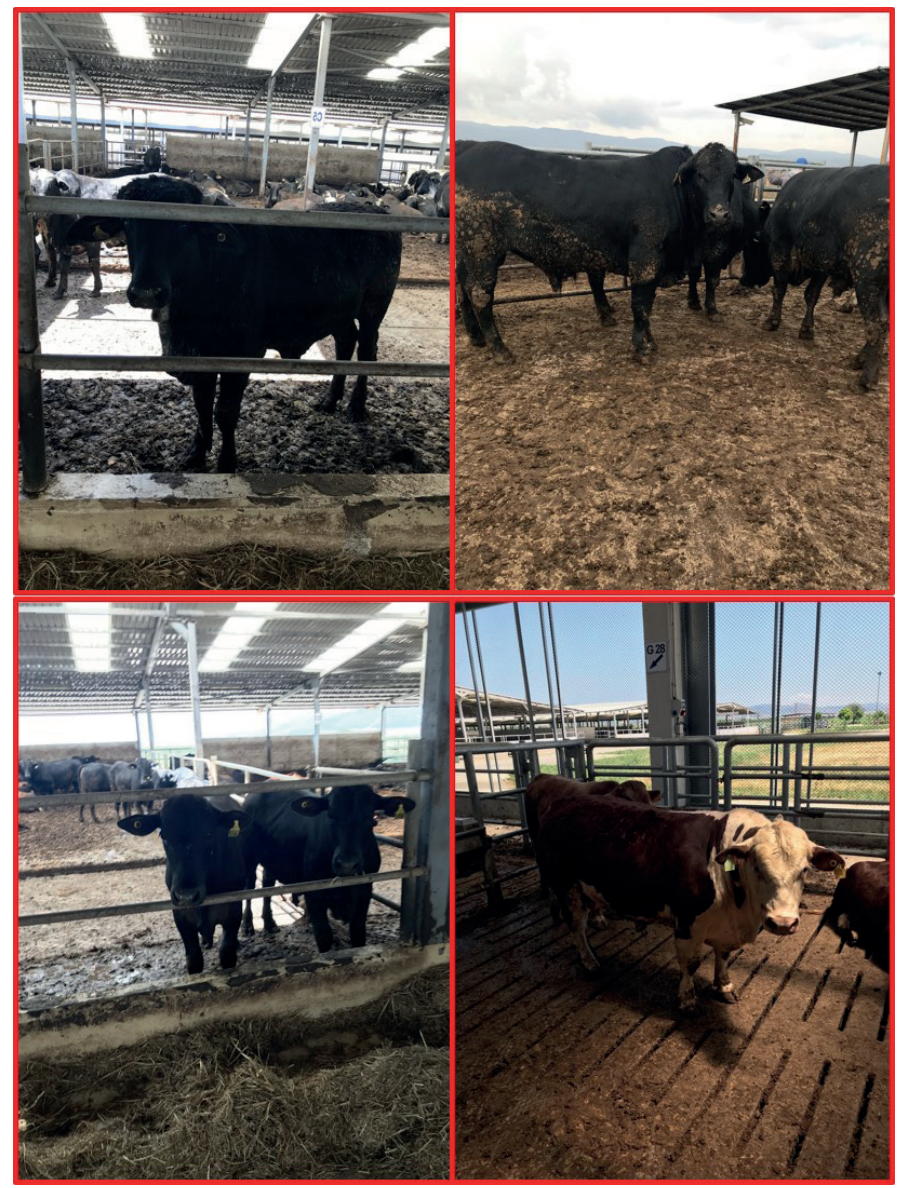

\section{Phenotypic traits}

The slaughter weight (SW) was measured before slaughter following a period of $12 \mathrm{~h}$ deprived of feed, but with full access to water. Hot carcass weight (HCW) was recorded after conventional slaughter processing and it was measured without removing the subcutaneous fat and keeping the kidney and pelvic fat. The carcasses were chilled at $4^{\circ} \mathrm{C}$ for approximately $24 \mathrm{~h}$ after which the cold carcass weights (CCW) were obtained. Carcass weights after chilling were likewise measured to determine the chilling loss (CL). The dressing percentage (DP) was estimated considering HCW. Carcass ph (24 h postmortem) was measured in the $\mathrm{m}$. longissimus thoracis between 12 th and 13th ribs using a calibrated $\mathrm{pH}$ probe (Testo $205 \mathrm{pH}$ meter, Lenzkirch, Germany).

\section{DNA extraction and the genotyping}

In this study, a 565 bp fragment in the exon 3 region of the FABP4 gene was amplified. Genomic DNA was isolated from white blood cells using standard techniques 13. The concentration and quality of DNA were detected by a NanoDrop spectrophotometer (NanoDrop 2000c, Thermo Scientific, Wilmington, DE, USA). The genotyping of the SNP was carried out by the PCR-RFLP method in a total of $25 \mu \mathrm{L}$ reaction volume. $3 \mu \mathrm{L}$ genomic DNA sample ( $\sim 60 \mathrm{ng}$ ) was used as a template. The reaction contained 
12.50 $\mu \mathrm{L}$ PCR master mix (OneTaq Quick-Load 2x MM with Standard Buffer, New England BioLabs Inc., Ipswich, Cat\#M0486S, USA), $1 \mu \mathrm{L}(0.5 \mu \mathrm{M})$ of each primer, and $8 \mu \mathrm{L}$ of nuclease-free water (Thermo Scientific). Oligonucleotide sequences ( 5 ' to $3^{\prime}$ ) were ACCCCTATGATGCTATTCCACA as the forward primer and ATACGGTTCACATTGAGAGGGA as the reverse primer 8. The amplification reaction was as follows: initial denaturation step at $95^{\circ} \mathrm{C}$ for $4 \mathrm{~min}, 35$ cycles of denaturation at $94^{\circ} \mathrm{C}$ for $1 \mathrm{~min}$, annealing at $60^{\circ} \mathrm{C}$ for $1 \mathrm{~min}$, and extension at $72^{\circ} \mathrm{C}$ for $1.5 \mathrm{~min}$, followed by a final extension step at $72^{\circ} \mathrm{C}$ for $5 \mathrm{~min} .15 \mu \mathrm{L}$ of PCR product (if verified) was digested with $10 \mathrm{U}$ of CviAII (isoschizomer of NlaIII) restriction enzyme (New England BioLabs, Cat\#R0640S), with 10x buffer (New England BioLabs) by incubating at $25^{\circ} \mathrm{C}$ for 16h. All PCR-RFLP reactions were performed in a thermal cycler (MyGenie 96 thermal block, Bioneer Corporation, South Korea). The resulting RFLP fragments were separated on $3 \%$ agarose gel by electrophoresis with $1 \times$ TBE buffer and were stained using ethidium bromide ( $2 \mu \mathrm{g} \mathrm{mL}-1)$. Gel photos were taken under UV light using a gel documentation system (DNR-Minilumi, DNR Bio-Imaging Systems, Israel).

\section{Statistical analysis}

The allelic and genotypic frequencies were estimated according to Falconer and Mackay. ${ }^{14}$ The Hardy-Weinberg equilibrium (HWE) was tested using the chi-square goodness-of-fit test. However, Fisher's exact test was used to evaluate HWE because of the low numbers of individuals per genotype (genotype counts below 5).

Indices of genetic diversity including effective allele numbers $(\mathrm{Ne})$ and the polymorphism information content (PIC) were calculated based on allele frequencies using appropriate formulas described by Botstein et al. ${ }^{15}$ and Nei and Roychoudhury ${ }^{16}$ as follows:

$$
\begin{gathered}
N e=1 / \sum_{i=1}^{n} P_{i}^{2} \\
P I C=1-\left(\sum_{i=1}^{n} P_{i}^{2}\right)-\sum_{i=1}^{n-1} \sum_{j=i+1}^{n} 2 P_{i}^{2} P_{j}^{2}
\end{gathered}
$$

where:

Pi was the frequency of the ith allele, $\mathrm{n}$ was the number of alleles.

Theoretical heterozygosity (Hthe) was calculated as:
$\mathrm{H}_{\text {the }}=1-\Sigma\left(p^{2}+q^{2}\right)$

The Fixation Index (FIS) was estimated from the values of Hthe and experimental (Hexp) heterozygosities using the following formula:

$\mathrm{F}_{\text {IS }}=\left(\mathrm{H}_{\text {the }}-\mathrm{H}_{\text {exp }}\right) / \mathrm{H}_{\text {the }}$

Theoretical homozygosity (E) was calculated as:

The level of possible variability realization (V\%) was estimated according to Crow and Kimura ${ }^{17}$ as follows:

$$
E=\sum p_{p_{\mathrm{i}}}
$$

where:

$$
V=\frac{1-E}{1-\frac{1}{N}} \times 100
$$

$\mathrm{E}=$ expected homozygosity

$\mathrm{N}=$ number of individuals in a population regarding a particular locus

The least-squares method as applied in a general linear model (GLM) procedure of Minitab software v19.1.1 was used to test the significance of the association of FABP4 c.328 G>A with slaughter weight and carcass traits. The selected statistical model is as follows:

$\mathrm{Y}_{\mathrm{ijklm}}=\mu+\mathrm{A}_{\mathrm{i}}+\mathrm{S}_{\mathrm{j}}+\mathrm{G}_{\mathrm{k}}+\mathrm{I}_{1}+\mathrm{e}_{\mathrm{ijklm}}$

where:

Yijklm = the studied traits,

$\mu=$ the overall mean,

$A i=$ the fixed effect of slaughter age ( $i=14-16$ months),

$S j=$ the fixed effect of slaughter season ( $j=$ spring and summer),

$\mathrm{Gk}=F A B P 4$ genotypes $(\mathrm{k}=\mathrm{AA}, \mathrm{GA}$, and $\mathrm{GG})$,

$\mathrm{Il}=$ two-way interactions,

eijklm $=$ random error.

Tukey's multiple comparison test was used; if significant effects were detected. Two-way interactions were statistically non-significant $(P>0.05)$, thus, they were excluded from the model and will not be considered further.

Additive and dominance effects were estimated according to Falconer and Mackay ${ }^{14}$ as follows:

The degree of dominance $=\mathrm{d} / \mathrm{a}$ where:

Additive effect $(\mathrm{a})=$ the difference between the means of 
two homozygous divided by two

Dominance effect $(d)=$ the heterozygote's deviation from the mean of the homozygotes

Overdominance can be indicated when $d$ is greater than + a or less than $-\mathrm{a}$.

\section{Results}

PCR-RFLP patterns

The electrophoresis pattern of PCR amplification for the FABP4 gene is shown in Figure 2. The cleavage of a $565 \mathrm{bp}$ PCR product (Fig 3) by CviAII yielded two fragments of
$233 \mathrm{bp}$ and $230 \mathrm{bp}$ and was diagnostic for the AA genotype. It is important to note that these fragments appear to be a single band because they are very close to each other. The GG genotype was characterized by 463 bp whereas three bands, $463 \mathrm{bp}, 233 \mathrm{bp}$, and $230 \mathrm{bp}$, were indicative for the heterozygous genotype (Figure 3 ).

Allelic and genotypic distributions and population genetic indices

The frequency of GG genotype in the FABP4 gene was found to be remarkably high in both Aberdeen Angus (49.18\%) and Hereford (52.94\%) bulls, as shown in Table

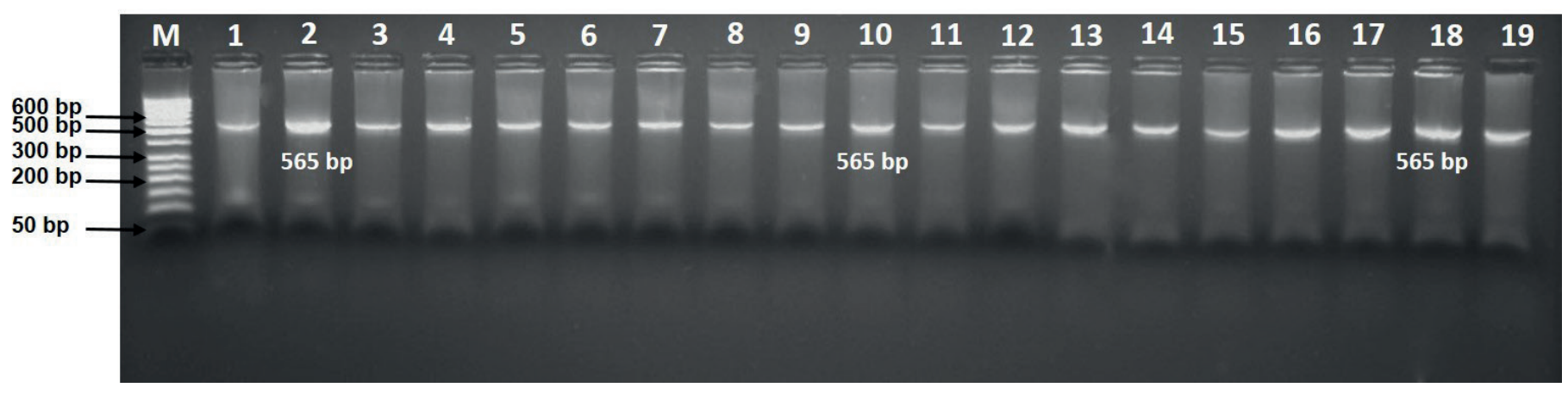

Figure 2. The electrophoresis pattern of PCR amplification (565 bp) for c.328 G>A polymorphism within the bovine FABP4 gene M: marker

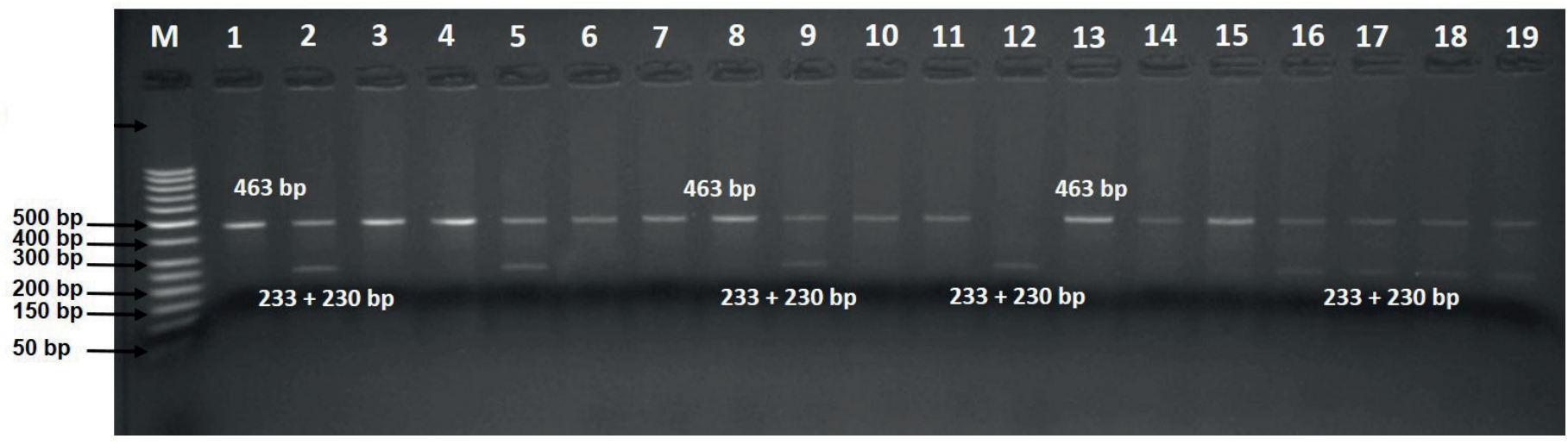

Figure 3. The electrophoresis pattern of restriction enzyme digestion with CviAII for c.328 G>A polymorphism within the bovine FABP4 gene. Line 12: AA genotype; Lines 1, 3, 4, 6-8, 10, 11, 13-15: GG; and Lines 2, 5, 9, 16-19: heterozygous genotype.

M: Marker.

Table 1. Genotype and allele frequencies of the SNP c.328 G>A of the bovine FABP4 gene in Aberdeen Angus and Hereford bulls.

\section{Genotype frequencies (\%)*}

Allele frequencies

Breed

$\boldsymbol{n}$
GA

$36.07(22)$

$35.29(12)$

$11.77(4)$

95

$35.79(34)$

34

$49.18(30)$

0.33

0.67

Hereford

Total

95

(35.79 (34)

$52.94(18)$

0.29

0.71

50.53 (48)

0.32

0.68 
1. Moreover, 48 out of 95 cattle were GG genotype carriers. For both breeds, the predominant allele was the G $(0.68$ in total). Only 9 and 4 cattle carry the AA genotype in the FABP4 c.328 G>A polymorphism in Aberdeen Angus and Hereford bulls, respectively. This resulted in a low frequenTable 2. Genetic diversity at the FABP4 gene in Aberdeen Angus and Hereford bulls.

\begin{tabular}{lccccccc}
\hline Breed & $\mathbf{H}_{\text {the }}$ & Ho & Ne & PIC & FIs & $V \%$ & Locus HWE test \\
\hline Aberdeen Angus & 0.4422 & 0.5578 & 1.7928 & 0.3444 & 0.5025 & 44.93 & Equilibrium $(P>0.05)$ \\
Hereford & 0.4118 & 0.5882 & 1.7001 & 0.3270 & 0.7086 & 42.42 & Equilibrium $(P>0.05)$ \\
Total & 0.4352 & 0.5648 & 1.7705 & 0.3405 & 0.2188 & 43.98 & Equilibrium $(P>0.05)$
\end{tabular}

cy of the A allele (0.32 in total).

HWE testing revealed that the population was determined to be compatible with the equilibrium $(\mathrm{P}>0.05)$. The population genetic indices are presented in Table 2. Ho was higher than 0.50 while the PIC was higher than 0.25 for both Aberdeen Angus and Hereford breeds. A considerable high level of FIS ( 0.71) was observed in Hereford bulls. Besides, Herefords had a higher V\% compared to Aberdeen Angus bulls. As shown in Table 2, an admissible

Table 3. Least square means for FABP4 c.328 G>A genotype effects on slaughter weights (kg) in Aberdeen Angus and Hereford bulls.

Breed

\section{Genotype}

AA $\quad$ GA $\quad$ GG

$P$-value

Aberdeen Angus

$581.10 \pm 14.60$

$594.99 \pm 9.00$

$565.88 \pm 7.81$

0.054

Hereford

$595.89 \pm 29.97$

$599.34 \pm 18.91$

$555.49 \pm 14.01$

0.137

Total

$591.27 \pm 8.51^{\mathrm{a}}$

$558.99 \pm 7.11^{\mathrm{b}}$

0.013

Table 4. Least square means for FABP4 c.328 G>A genotype effects on carcass traits in Aberdeen Angus bulls.

\section{Genotype}

Trait
AA
GA
GG

$P$-value

\begin{tabular}{lcccc}
\hline Hot carcass weight $(\mathrm{kg})$ & $312.88 \pm 9.42$ & $301.69 \pm 6.45$ & $300.89 \pm 7.27$ & 0.487 \\
Cold carcass weight $(\mathrm{kg})$ & $307.83 \pm 9.43$ & $296.30 \pm 6.46$ & $295.74 \pm 7.28$ & 0.476 \\
Chilling loss (kg) & $5.05 \pm 0.21$ & $5.38 \pm 0.14$ & $5.15 \pm 0.16$ & 0.299 \\
Dressing percentage (\%) & $54.28 \pm 0.77$ & $55.15 \pm 0.53$ & $54.05 \pm 0.59$ & 0.311 \\
Carcass pH at 24 h & $5.54 \pm 0.09$ & $5.53 \pm 0.05$ & $5.56 \pm 0.04$ & 0.897
\end{tabular}


Ne level $(>0.70)$ was found in the studied population.

\section{Marker effects on trait means}

Concerning the association between the FABP4 genotypes and the SW, levels of significance are reported in Table 3. Heterozygous animals had higher SW compared to alternative genotypes. However, this association was substantiated in only the total cattle population $(\mathrm{P}<0.05)$. As shown in Table 4, the association of the FABP4 genotypes with carcass weights, CL, DP, and $\mathrm{pH}(24 \mathrm{~h})$ was found to be non-significant.

\section{Discussion}

In genetic association studies, the evaluation of population genetics characteristics plays a key role in achieving reliable and confidential results. These parameters can provide valuable information on the strength and conformity of the genetic marker regarding the selected phenotypes. Moreover, they display the breeding properties of the selected animal population, such as eventual inbreeding.9,18 Based on the results of the $\chi^{2}$ test, genotype frequencies of the SNP were in compliance with HWE in both breeds.

Table 5. Additive and dominance effects of the marker with the significant association in the studied population $(n=95)$.

\begin{tabular}{lccc}
\hline Trait & Additive effect & Dominant effect & Overdominance \\
\hline Slaughter weight & 11.315 & $20.965^{*}$ & + \\
\hline
\end{tabular}

Besides moderate levels of population genetic indices were observed for $\mathrm{He}, \mathrm{Ne}$, and PIC (Table 2). According to the interpretation by Botstein et al.15, PIC can be classified into three main groups as follows: PIC $>0.50$ (high polymorphism), $0.25<\mathrm{PIC}<0.50$ (moderate polymorphism), and $\mathrm{PIC}<0.25$ (low polymorphism). Thus the FABP4 marker in this study can be evaluated as mildly informative for Aberdeen Angus and Hereford cattle. On the other hand, undesirable levels of FIS and V\% were found in Hereford bulls. The main reason is that the sample size was rather limited in Herefords. Moreover, the Ho level was the highest in this breed ( 0.6).

Importation of cattle has become a frequently used method to maintain the balance between supply and demand in Turkey. However, farms generally do not perform genotypic analyses on beef cattle to be imported. ${ }^{19}$ This can lead to controversial situations about the origin and genotypic status of animals and even their breed purity. Breed registries have been established for livestock species to maintain the purity of breeds and to document the ancestry of animals. However, a significant number of animals are unregistered with no or incomplete pedigree data and uncertain ances- tral breed origin. ${ }^{20}$ The SNP rs110652478 has been suggested to be monomorphic in Creole, Hereford, Limousin, and Brahman breeds. ${ }^{6}$ However, in this study, we observed all three genotypes in Herefords (even if there was an unbalanced genotypic distribution). Genetic assessment can prevent controversial results and inconsistencies between literature (previously reported genotypic distributions) and the observed results in the field. There are also newly developed genetic tools for determining the breed purity of cattle. ${ }^{20}$

In the last few decades, the main focus on animal breeding in many countries has gradually changed from conventional phenotype-based evaluation to molecular genetic analysis. These molecular techniques are rather confidential and effective for selecting animals with superior performance in specific desirable traits. In the present study, the association of FABP 4 c.328 G>A with slaughter weight and certain carcass traits was tested in Aberdeen Angus and Hereford bulls. The FABP4 c.328 G>A genotype effect was strongly significant for slaughter weight $(\mathrm{P}=0.01)$, with the heterozygous animals associated with increased slaughter weight $(591.27 \pm 8.51 \mathrm{~kg})$ concerning total cattle population. The GA genotype carriers had $+9.65 \mathrm{~kg}$ and $32.28 \mathrm{~kg}$ higher slaughter weights compared to the AA and GG animals, respectively. The corresponding estimates indicated significant overdominance (Table 5). This interpretation was not substantiated in breed-specific evaluation, although heterozygous animals were heavier than alternative genotype carriers. But it is important to note that the association of $F A B P 4$ with slaughter weight approached statistical significance $(\mathrm{P}=0.054)$. Although FABP4 is a leading genetic marker for meat quality traits, especially marbling ${ }^{2,5,8}$, some papers are indicating a potential effect of this gene on live and carcass weight. In this context, Lee et al. $^{21}$ showed that the FABP4 microsatellite (3237AT) marker had a significant effect on live weight in Hanwoo. A SNP located in intron 1 of the FABP4 (g.2834C >G) was associated with desirable increases in live weight, hot carcass weight, and chilled carcass weight. ${ }^{2}$ On the other hand, in Holstein bulls, a potential novel effect of FABP4 gene polymorphisms on average daily weight gain was shown by Ardicli et al. ${ }^{9}$ This gene was associated with carcass weight in various commercial beef cattle populations. Mizoshita et al. ${ }^{22}$ demonstrated that a quantitative trait loci (QTL) for carcass weight in purebred Japanese Black (Waygu) is close to the FABP4 gene on BTA14. Moreover, Lee et al. ${ }^{12}$ suggested that the genetic polymorphisms of the FABP4 gene (g.3473T $>A$ and $2774 \mathrm{G}>\mathrm{C}$ ) are significantly associated with carcass weight in Hanwoo (Korean Cattle). They also found that the CAG haplotype effect for carcass weight was larger than the largest single-locus effect of g.3473A $>$ T. In 
this study, non-significant differences among FABP4 genotypes were found for hot and cold carcass weights. In a similar vein, studies conducted on different cattle breeds have reported that FABP4 may have limited influences on live weight and carcass traits. ${ }^{23-25}$ In some cases, unbalanced distribution of the alleles, limited sample sizes, and remarkably low frequencies of alleles may be the potential reasons for the non-significant phenotype-genotype interactions. ${ }^{23,24} \mathrm{On}$ the other hand, the genetic composition of the selected breeds and/or polygenic effects associated with the expression of the studied traits are important factors to be considered. FABPs (especially FABP4 and FABP5) have been proposed as potential candidate genes for obesity as they are located within a QTL region. ${ }^{8}$ From a broader point of view, FABP4 would be potentially relevant to elucidate the influence of this genomic region concerning live weight and carcass traits.

The bovine FABP4 gene was hypothesized to be a genetic factor influencing intramuscular fat deposition and subcutaneous fat in muscle. ${ }^{5,8,26-29}$ It has been suggested to be one of the major metabolic indicators of intramuscular fat deposition ability. ${ }^{28}$ Cho et al. ${ }^{11}$ reported that FABP4 c.220A $>\mathrm{G}$ polymorphism in exon 2 significantly affects BFT in Korean cattle. Ardicli et al. ${ }^{2}$ demonstrated that g.3691G $>$ A $\times$ g.2834C $>\mathrm{G}$ interaction was effective on the BFT in Holstein bulls. In the present study, however, no association of FABP4 marker with BFT was observed. Moreover, there was no significant effect of this gene on CL, DP, and $\mathrm{pH}$ (24h). As suggested by Barton et al. ${ }^{28}$ and Aviles et al. ${ }^{26}$, the effects of genetic markers are often breed-specific and they are not eligible for all cattle populations. Furthermore, it is worth noting that, the sample size for association analyzes in this study was rather limited because crossbreds and the animals with missing information were excluded from the genetic analyses to prevent unreliable results. Thus, studies performed with larger populations may be needed for confirmation.

Evaluation of genotype-phenotype interactions based on economically important traits will provide significant insights into Turkey's livestock breeding. Genetic interpretation is crucial not only in cattle raised in Turkey but also in cattle to be imported. ${ }^{19}$ The important point to note here is that marker-assisted selection (MAS) has advantages compared to conventional phenotype-based selection methods. However, MAS cannot provide a widespread use of DNA information in animal breeding. The main reason was that many functional traits in livestock are much more complex than expected. In traits under polygenic inheritance, small effects are usually ignored and make it difficult to evaluate. ${ }^{30}$ Genome-wide approaches have become more common in many European countries and the USA. Unfortunately, Turkey is far behind in terms of genomic applications in animal breeding. Hence genetic studies in Turkey should be encouraged to provide a more profitable and sustainable cattle breeding management, even if they may have preliminary suggestions compared to studies conducted by the developed countries with high budgets.

\section{Conclusions}

This study focused on the c.328 G>A polymorphism located on exon 3 of the bovine FABP4 gene and its genetic diversity and effects on slaughter weight and certain carcass traits. The heterozygous genotype was significantly associated with increased slaughter weight and seemed to be desirable in the evaluation of the total population. This association was not confirmed in breed-specific analyzes. Moreover, there was no association of the FABP4 with hot and cold carcass weight, chilling loss, dressing percentage, and carcass $\mathrm{pH}$. Consequently, it can be interpreted that FABP4 c.328 G>A marker may provide valuable, but limited, information on imported beef cattle raised in Turkey conditions.

\section{Acknowledgment}

The authors gratefully thank Tabiat Agriculture Farm (Bursa) and Oguz Kandazoglu for their contribution. This study does not contain any invasive procedures in animals performed by any of the authors. Thus, no ethics statement is required for this work because the samples were obtained from flowing blood during standard exsanguination in the slaughterhouse.

\section{References}

1. Goddard M, Hayes B. Genomic selection. Journal of Animal breeding and Genetics 2007;124:323-330.

2. Ardicli S, Samli H, Alpay F, et al. Association of single nucleotide polymorphisms in the FABP4 gene with carcass characteristics and meat quality in Holstein bulls. Annals of Animal Science 2017;17:117-130.

3. Switonski M. Molecular genetics in beef cattle breeding-a review. Animal Science Papers and Reports 2002;20:7-18.

4. Casas E, Shackelford S, Keele J, et al. Detection of quantitative trait loci for growth and carcass composition in cattle. Journal of Animal Science 2003;81:2976-2983.

5. Michal J, Zhang Z, Gaskins C, et al. The bovine fatty acid binding protein 4 gene is significantly associated with 
marbling and subcutaneous fat depth in Wagyu x Limousin F2 crosses. Animal Genetics 2006;37:400-402.

6. Goszczynski DE, Papaleo-Mazzucco J, Ripoli MV, et al. Genetic variation in FABP4 and evaluation of its effects on beef cattle fat content. Animal biotechnology 2017;28:211-219.

7. Fortes MR, Curi RA, Chardulo LAL, et al. Bovine gene polymorphisms related to fat deposition and meat tenderness. Genetics and Molecular Biology 2009;32:75-82.

8. Shin S-C, Heo J-P, Chung E-R. Genetic variants of the $F A B P 4$ gene are associated with marbling scores and meat quality grades in Hanwoo (Korean cattle). Molecular biology reports 2012;39:5323-5330.

9. Ardicli S, Samli H, Vatansever B, et al. Comprehensive assessment of candidate genes associated with fattening performance in Holstein-Friesian bulls. Archives Animal Breeding 2019;62:9-32.

10. Maharani D, Jung Y, Jung W, et al. Association of five candidate genes with fatty acid composition in Korean cattle. Molecular biology reports 2012;39:6113-6121.

11. Cho S, Park T-S, Yoon D-H, et al. Identification of genetic polymorphisms in FABP3 and FABP4 and putative association with back fat thickness in Korean native cattle. BMB reports 2008;41:29-34.

12. Lee SH, Van Der Werf J, Lee S, et al. Genetic polymorphisms of the bovine fatty acid binding protein 4 gene are significantly associated with marbling and carcass weight in Hanwoo (Korean Cattle). Animal genetics 2010;41:442-444.

13. Sambrook J, Russell DW. Isolation of High-molecular-weight DNA from Mammalian Cells Using Formamide. Cold Spring Harbor Protocols 2006;2006:pdb. prot3225.

14. Falconer DS, Mackay TFC. Introduction to quantitative genetics, Pearson Education Ltd, Harlow, England; 1996.

15. Botstein D, White RL, Skolnick M, et al. Construction of a genetic linkage map in man using restriction fragment length polymorphisms. American journal of human genetics 1980;32:314.

16. Nei M, Roychoudhury A. Sampling variances of heterozygosity and genetic distance. Genetics 1974;76:379-
390.

17. Crow JF, Kimura M. Properties of a finite population. In: An introduction to population genetics theory. The Blackburn Press, Caldwell, New Jersey: 319-365; 1970.

18. Trakovická A, Moravčíková N, Kasarda R. Genetic polymorphisms of leptin and leptin receptor genes in relation with production and reproduction traits in cattle. Acta Biochimica Polonica 2013;60.

19. Ardicli S, Ustüner H, Arslan Ö, et al. Variability of CAPN1 g. 5709 C> G and MYF5 g. 1911 A> G Polymorphisms in Beef Cattle Imported from Brazil to Turkey. Lalahan Hayvancılık Araştırma Enstitüsü Dergisi 2019;59:72-78.

20. Hulsegge I, Schoon M, Windig J, et al. Development of a genetic tool for determining breed purity of cattle. Livestock Science 2019;223:60-67.

21. Lee S-H, Cho Y-M, Kim H-C, et al. Association of microsatellite marker in FABP4 gene with marbling score and live weight in Hanwoo. Journal of Animal Science and Technology 2010;52:475-480.

22. Mizoshita K, Watanabe T, Hayashi H, et al. Quantitative trait loci analysis for growth and carcass traits in a half-sib family of purebred Japanese Black (Wagyu) cattle. Journal of Animal Science 2004;82:3415-3420.

23. Ayres D, Souza F, Mercadante M, et al. Evaluation of TFAM and FABP4 gene polymorphisms in three lines of Nellore cattle selected for growth. Genetics and Molecular Research 2010:2050-2059.

24. Ardicli S, Dincel D, Samli H, et al. Effects of polymorphisms at LEP, CAST, CAPN1, GHR, FABP4 and DGAT1 genes on fattening performance and carcass traits in Simmental bulls. Archives Animal Breeding 2017;60:61-70.

25. Cinar MU, Akyuz B, Kiyici JM, et al. Effects of GHAluI and MYF5-TaqI polymorphisms on weaning weight and body measurements in Holstein young bulls. Kafkas Universitesi Veteriner Fakültesi Dergisi 2018;24:873-880

26. Avilés C, Polvillo O, Peña F, et al. Associations between DGAT1, FABP4, LEP, RORC, and SCD1 gene polymorphisms and fat deposition in Spanish commercial beef. Journal of Animal Science 2013;91:4571-4577. 
27. Barendse W, Bunch R, Thomas M, et al. A splice site single nucleotide polymorphism of the fatty acid binding protein 4 gene appears to be associated with intramuscular fat deposition in longissimus muscle in Australian cattle. Animal Genetics 2009;40:770-773.

28. Bartoň L, Bureš D, Kott T, et al. Associations of polymorphisms in bovine DGAT1, FABP4, FASN, and PPARGC1A genes with intramuscular fat content and the fatty acid composition of muscle and subcutaneous fat in Fleckvieh bulls. Meat Science 2016;114:18-23.

29. Thaller G, Kühn C, Winter A, et al. DGAT1, a new positional and functional candidate gene for intramuscular fat deposition in cattle. Animal Genetics 2003;34:354357.

30. Meuwissen T, Hayes B, Goddard M. Genomic selection: A paradigm shift in animal breeding. Animal Frontiers 2016;6:6-14. 